\title{
First trimester combined screening in patients with systemic lupus erythematosus: impact of pre-analytical variables on risk assessment
}

\author{
Maria José Rego de Sousa ${ }^{1}$ (D) Rita Ribeiro ${ }^{1} \cdot$ Argyro Syngelaki $^{2} \cdot$ Kypros H. Nicolaides $^{2}$
}

Received: 20 January 2019 / Accepted: 18 March 2019 / Published online: 28 March 2019

(C) The Author(s) 2019

\begin{abstract}
Background Prenatal diagnosis of fetal trisomy 21 and other chromosomal abnormalities is based on invasive tests, such as amniocentesis and chorionic villus sampling, which are carried out in women identified through screening as being at high risk for these abnormalities. The most widely used method of screening is the first-trimester combined test which utilizes maternal age, and measurements of fetal nuchal translucency thickness (NT) and maternal serum pregnancy-associated plasma protein-A (PAPP-A) and free $\beta$-human chorionic gonadotropin (hCG).

Objectives To assess the influence of SLE on the levels of NT, PAPP-A, and $\beta$-hCG and whether any alterations in such levels may increase the rate of false positives and the subsequent number of invasive tests.

Method This was a prospective first-trimester screening study for trisomies 21,18 , and 13 by a combination of maternal age, fetal nuchal translucency thickness, and serum PAPP-A and $\beta$-hCG at King's College Hospital, London, between March 2006 and February 2011. The study population included 47 cases with maternal SLE and 45,493 without SLE. The results of biomarkers in the SLE and non-SLE groups were compared.

Results In the SLE group, compared to the non-SLE group, there were no significant differences in median maternal age, fetal NT, or serum PAPP-A MoM, but serum free $\beta$-hCG MoM was increased (1.402, IQR 0.872-2.290 vs 0.994, IQR 0.676-1.508). Conclusion In first trimester screening for trisomies, the measured value of free $\beta$-hCG should be adjusted for maternal SLE to avoid false positive results and overuse of invasive tests.
\end{abstract}

Keywords First trimester combined screening $\cdot$ Prenatal diagnosis $\cdot$ Systemic lupus erythematosus $\cdot$ Trisomies

\section{Introduction}

Chromosomal abnormalities are major causes of perinatal death and disability in childhood. Prenatal diagnosis of fetal trisomy 21 and other chromosomal abnormalities is based on invasive tests, such as amniocentesis and chorionic villus sampling, which are carried out in women identified through

Key point The authors argue that SLE can influence the results of first trimester screening, namely an increase of the rate of false positive results. Therefore, it is important to have a correction factor in the risk algorithm to prevent an increase in the number of invasive tests.

Maria José Rego de Sousa

mariajsousa@cm-lab.com

1 Autoimmunity Unit, Centro de Medicina Laboratorial Germano de Sousa, R. Cupertino de Miranda, 1600-513 Lisbon, Portugal

2 Harris Birthright Research Center of Fetal Medicine, King's College Hospital, London, UK screening as being at high risk for these abnormalities. The most widely used method of screening is the first trimester combined test which utilizes maternal age, and measurements of fetal nuchal translucency thickness and maternal serum pregnancy-associated plasma protein-A (PAPP-A) and free $\beta$-human chorionic gonadotropin $(\beta-h C G)[1-3]$. Accurate assessment of risk for trisomies necessitates reliable measurements and interpretation of serum PAPP-A and free $\beta-\mathrm{hCG}$ since failure to do so would result in overestimation or underestimation of the risk with potentially serious consequences. Some case reports and small series in women with systemic lupus erythematosus (SLE) reported that serum levels of hCG in the second and third trimesters of pregnancy may be increased or decreased [4-6]. A study in 10 pregnant women with SLE and 1140 without preexisting maternal disease reported that in the SLE group first trimester serum free B-hCG levels were increased, but in view of the study's limited statistical power, no significant differences were detected in the rates of false positives after combined first trimester screening 
for trisomies [7]. It was therefore concluded that in pregnant women with SLE the risk for trisomy 21 would not be affected, and that combined first trimester screening could continue to be used in that population without significant problems.

SLE is a systemic autoimmune chronic inflammatory disease affecting $20-70$ per 100,000 of the general population [8]. Main manifestations range from fatigue and arthralgias to nephritis, pneumonitis, and cardiac disorders, with immense impact on the quality of life of patients, when combined with frequent side effects from treatment [9]. Females have a 2.7-fold higher risk of having an autoimmune disease when compared to males. In the case of SLE, the female to male ratio is 9 to 1 and the incidence is 10 times higher at puberty, and the flares are more intense during the premenstrual period and in pregnancy [10]. Although female predominance has been known for more than a century, the causes of this imbalance remain unknown and several theories have been proposed [11] including hormonal, reproductive, fetal microchemistry, X chromosome inactivation and X chromosome anomalies [12]. The increase of the flares in the course of pregnancy supports the influence that mainly estrogens may have on the progression of SLE [12]. In the hypothesis of fetal microchimerism, defined by the persistence of immunocompetent fetal cells in the maternal circulation years after postpartum, this could be implicated in the pathogenesis of autoimmune diseases in women. Although the evidence was weak or inconclusive, this theory has evolved towards a complex generational microchimerism found in some autoimmune diseases such as diabetes mellitus type I, rheumatoid arthritis, autoimmune thyroid disease [11]. Another explanatory hypothesis about the predominance of autoimmune diseases in women resides in the inactivation of the $\mathrm{X}$ chromosome and the consequent escape, in 10-15\%, of the self-antigens linked to $\mathrm{X}$, the mechanisms of induction of tolerance, central and peripheral. Associated with this inactivation, there is also the so-called inactivation skewing ( $>75 \%$ of genes linked to $\mathrm{X}$ are inactivated) or extreme inactivation skewing (>90\% of genes linked to $\mathrm{X}$ are inactivated): women are mosaics of $\mathrm{X}$ linked genes [11]. Epigenetic activation of the inactive $\mathrm{X}$ chromosome genes may also lead to a self-antigen immune reaction. The occurrence of SLE in males is similar to that in postmenopausal or prepubertal women. However, there is a 14-fold higher risk of SLE in men with Klinefelter's syndrome (i.e., XXY genotype), with the mechanism of inactivation and skewing being an important common feature [13, 14]. On the other hand, in Turner's syndrome, women rarely have SLE, although there is an observed incidence of autoimmune disorders [12]. In primary biliary cirrhosis (PBC), the female to male ratio is about 10:1, and it was found by Bianchi et al. [15], that women with PBC have a higher prevalence of loss of $\mathrm{X}$ chromosome, but these patients do not seem to have higher prevalence of $\mathrm{PBC}$, although they are prone to autoimmune diseases.
Given the limited number of published studies and their respective limited number of cases, the possible influence of SLE on serum free $\beta-h C G$ and PAPP-A levels in the first trimester of pregnancy is yet to be properly evaluated. The aim of this study is to evaluate the influence of SLE on the levels of free $\beta-\mathrm{hCG}$ and PAPP-A used in first trimester prenatal combined screening and to determine whether SLE may increase the rate of false positive results, with a consequent increase in the number of invasive tests.

\section{Methods}

The study population is 48,303 singleton pregnancies undergoing screening for fetal trisomies at $11^{+0}-13^{+6}$ weeks of gestation at the Harris Birthright Research Center of Fetal Medicine-King's College Hospital (London) between March 2006 and February 2011. Maternal demographic characteristics were recorded, ultrasound examination was carried out to determine the gestational age from the measurement of the fetal crown-rump length (CRL) and measurement of fetal nuchal translucency (NT) thickness and serum PAPP-A and free $\beta-h C G$ concentrations were determined with automated equipment (Delfia Xpress system, PerkinElmer Life and Analytical Sciences, Waltham, USA). The measured concentrations of PAPP-A and free B-hCG were converted to multiples of the normal median (MoM) after adjustment for gestational age, maternal racial origin, cigarette smoking, method of conception, and parity [3]. The risk for trisomies 21, 18, and 13 was calculated and if this was more than 1 in 100 an invasive test was carried out to determine the fetal karyotype. Details on pregnancy outcome were added to the database as soon as they were available.

Results were described through means, medians, interquartile ranges (IQR), absolute and relative frequencies. Regarding the prenatal screening algorithm performance measures, data about the detection rate, false positive and false negative rates, positive and negative predictive values, sensitivity and specificity were estimated. Variance analysis (ANOVA) and the Student $t$ test ( $t$ test for unpaired samples) were used to compare means in two normal distribution groups; the Mood test and the Kruskal-Wallis test for medians were used to compare the samples of two groups in which the data did not present normal distribution. The binomial 2 Proportion Test was used to analyze proportions or percentages from different samples.

\section{Results}

The study population of 45,540 pregnancies was divided into 47 with and 45,493 without SLE. The characteristics of the study population are summarized in Table 1. In the SLE group, compared to the non-SLE group, median gestational age at delivery and birthweight were lower. The findings of 
Table 1 Sample characteristics

\begin{tabular}{|c|c|c|}
\hline Variable & Non-SLE group $(n=45,493)$ & $\operatorname{SLE}(n=47)$ \\
\hline Maternal age (years), median (IQR) & $32.0(27.78-35.7)$ & $31.8(28.2-35.0)$ \\
\hline Body mass index $\left(\mathrm{kg} / \mathrm{m}^{2}\right)$, median (IQR) & $24.3(21.9-27.8)$ & $25.4(21.7-30.3)$ \\
\hline \multicolumn{3}{|l|}{ Ethnicity, n (\%) } \\
\hline Caucasian & $32,077(70.5)$ & $35(74.5)$ \\
\hline African & $9169(20.2)$ & $9(19.2)$ \\
\hline East Asian & $1000(2.2)$ & $0(0.0)$ \\
\hline South Asian & $1956(4.3)$ & $5(10.0$ \\
\hline Mixed & $1291(2.8)$ & $1(2.0)$ \\
\hline Smoking while pregnant, $n(\%)$ & $3595(7.9)$ & $3(6.0)$ \\
\hline \multicolumn{3}{|l|}{ Conception, $n(\%)$} \\
\hline Spontaneous & $43,903(96.5)$ & $44(93.6)$ \\
\hline Ovulation drugs & $722(1.6)$ & $2(4.3)$ \\
\hline In vitro fertilization & $868(1.9)$ & $1(2.1)$ \\
\hline \multicolumn{3}{|l|}{ Parity, $n(\%)$} \\
\hline Nulliparous & $22,140(48.7)$ & $19(40.4)$ \\
\hline Multiparous & $23,353(51.3)$ & $28(59.6)$ \\
\hline \multicolumn{3}{|l|}{ Medical history, $n(\%)$} \\
\hline Type I diabetes & $208(0.5)$ & $0(0.0)$ \\
\hline Type II diabetes & $136(0.3)$ & $0(0.0)$ \\
\hline Chronic hypertension & $567(1.3)$ & $2(4.3)$ \\
\hline Gestational age at birth in $w$, median (IQR) & $40.1(39.0-41.0)$ & $39.0(37.7-40.3) * *$ \\
\hline Weight at birth in gr, median (IQR) & $3400(3080-3724)$ & $3090(2815-3569) *$ \\
\hline
\end{tabular}

the first trimester combined test in the SLE and non-SLE groups are compared in Table 2. In the SLE group, compared to the non-SLE group, there were no significant differences in median maternal age, fetal NT, or serum PAPP-A MoM, but serum free $\beta$-hCG MoM was increased (1.402, IQR 0.872-
2.290 vs 0.994 , IQR 0.676-1.508). There was no significant difference in the proportion of the two groups that was screen positive (risk $>1$ in 100) based on maternal age, but in the SLE group there was a significantly higher proportion of women with a screen positive result from the combined test.
Table 2 First trimester markers in the SLE and non-SLE groups

\begin{tabular}{lll}
\hline Variables & Non-SLE group $(n=45,493)$ & SLE group $(n=47)$ \\
\hline Gestational age at exam in weeks, median (IQR) & $12.7(12.4-13.1)$ & $12.6(12.4-13.1)$ \\
Ultrasonography markers & & \\
Crown-rump length in mm, median (IQR) & $63.5(58.6-69.0)$ & $61.9(59.1-68.1)$ \\
Nuchal translucency thickness in mm, median (IQR) & $1.8(1.6-2.1)$ & $1.8(1.5-2.0)$ \\
Biochemistry markers & & \\
PAPP-A, U/L, median (IQR) & $2.83(1.79-4.42)$ & $2.14(1.34-4.80)$ \\
PAPP-A, MoMs, median (IQR) & $1.003(0.686-1.426)$ & $0.972(0.589-1.638)$ \\
Free $\beta-h C G$, U/L, median (IQR) & $36.50(24.30-56.20)$ & $51.10(29.80-79.10)^{*}$ \\
Free $\beta$-hCG, MoMs, median (IQR) & $0.994(0.676-1.508)$ & 1.402 \\
& & $(0.872-2.290)^{* *}$ \\
Results of the combined test & $4.6 \%$ & $8.5 \%$ \\
Positive screening-maternal age risk (\%) & $3.8 \%$ & $14.9 \% *$ \\
Positive screening-combined risk $(\%)$ & $3.2 \%$ & $8.5 \%$ \\
False positive rate (combined risk) $(\%)$ & & \\
\hline
\end{tabular}

PAPP-A, plasma protein-A; $\beta$-hCG, $\beta$-human chorionic gonadotropin; MoM, multiple of the median $* p<0.05, * * p<0.01$ 


\section{Discussion}

The findings this large first-trimester screening study for fetal trisomies 21, 18, and 13 demonstrate that the incidence of SLE is about $1 \%$ and that in this condition maternal serum free $\beta$ $\mathrm{hCG}$ is increased with a consequent increase in the screen positive rate. Although the false positive rate in the SLE group was higher than in the non-SLE group ( $8.5 \%$ vs. $3.2 \%)$, this difference did not reach statistical significance. Our finding of increased serum free $\beta$-hCG in patients with SLE is consistent with those of a previous first trimester study in 10 affected pregnancies [7]; however, in contrast to the previous study, we found that the increase in free $\beta-\mathrm{hCG}$ was associated with an overall increase in the screen positive rate.

In the past, it was advised that women with SLE should not get pregnant [16]. Better understanding of the pathophysiology of the disease and establishment of multidisciplinary intervention models have now improved the prognosis of pregnancy in such patients $[17,18]$. However, pregnancy in patients with SLE and other autoimmune disorders is still a condition carrying some risks for both the mother and baby. These include miscarriage, prematurity, fetal growth disorders, and fetal death, which are thought to be the consequence of immunological changes in the placenta [19-24]. In our study, we did not have any cases of SLE-related miscarriages or fetal deaths but the median gestational age at delivery and birthweight in pregnancies of women with SLE were lower than in those without SLE.

The proportion of pregnancies with SLE in the population undergoing screening is small and therefore the observed increase in serum free $\beta$-hCG MoM in such women would not have a global effect on the performance of screening. However, in women with SLE higher levels of free $\beta$-hCG would result in increased rate of invasive testing and would subject such women to an unnecessary risk of a procedurerelated miscarriage. In order to avoid such a practice, it would be necessary to include SLE as an additional factor that should be taken into account in the estimation of MoM values [3].

The main limitation of our results arises from the relatively small number of cases of SLE compared to those without SLE because the level of reliability of the performance indicators decreases when the pathology under analysis has a low prevalence. Therefore, the interpretation of such indicators must be carried out with extreme care.

We conclude that first-trimester combined screening for trisomies should continue to be offered to pregnant women with SLE. However, it is necessary to introduce a correction factor in the risk algorithm in order to avoid an increase in the number of false-positive results and consequent increase in the rate of invasive tests.

Funding The study was supported by grants from the Fetal Medicine Foundation (charity no. 1037116).

\section{Compliance with ethical standards}

Disclosures None.

Open Access This article is distributed under the terms of the Creative Commons Attribution 4.0 International License (http:// creativecommons.org/licenses/by/4.0/), which permits unrestricted use, distribution, and reproduction in any medium, provided you give appropriate credit to the original author(s) and the source, provide a link to the Creative Commons license, and indicate if changes were made.

\section{References}

1. Nicolaides KH (2011) Screening for fetal aneuploidies at 11 to 13 weeks. Prenat Diagn 31:7-15

2. Spencer K, Souter V, Tul N, Snijders R, Nicolaides KH (1999) A screening program for trisomy 21 at 10-14 weeks using fetal nuchal translucency, maternal serum free beta-human chorionic gonadotropin and pregnancy-associated plasma protein-a. Ultrasound Obstet Gynecol 13:231-237

3. Kagan KO, Wright D, Spencer K, Molina FS, Nicolaides KH (2008) First-trimester screening for trisomy 21 by free betahuman chorionic gonadotropin and pregnancy-associated plasma protein-A: impact of maternal and pregnancy characteristics. Ultrasound Obstet Gynecol 31:493-502

4. Ferriman EL, Sehmi IK, Jones R, Railton A, Hilton RC, Cuckle HS (2000) False-positive maternal serum screening in systemic lupus erythematosis: a case report. Prenat Diagn 20:851

5. Maymon R, Cuckle H, Sehmi IK, Herman A, Sherman D (2001) Maternal serum human chorionic gonadotrophin levels in systemic lupus erythematosus and antiphospholipid syndrome. Prenat Diagn 21:143-145

6. Clark F, Dickinson JE, Walters BN et al (1995) Elevated midtrimester hCG and maternal lupus anticoagulant. Prenat Diagn 15: 1035-1039

7. Heinig J, Steinhard J, Schmitz R, Nofer JR, Kiesel L, Klockenbusch W (2007) Influence of maternal systemic lupus erythematosus on first-trimester combined screening for chromosomal abnormalities. Prenat Diagn 27:600-602

8. Kariuki SN, Ghodke-Puranik Y, Dorschner JM, Chrabot BS, Kelly JA, Tsao BP, Kimberly RP, Alarcón-Riquelme ME, Jacob CO, Criswell LA, Sivils KL, Langefeld CD, Harley JB, Skol AD, Niewold TB (2015) Genetic analysis of the pathogenic molecular sub-phenotype interferon-alpha identifies multiple novel loci involved in systemic lupus erythematosus. Genes Immun 16:15-23

9. Oomatia A, Fang H, Petri M, Birnbaum J (2014) Peripheral neuropathies in systemic lupus erythematosus: clinical features, disease associations, and immunologic characteristics evaluated over a twenty-five-year study period. Arthritis Rheum 66:1000-1009

10. Lateef A, Petri M (2012) Hormone replacement and contraceptive therapy in autoimmune diseases. J Autoimmun 38:J170-J176

11. Selmi C, Brunetta E, Raimondo MG, Meroni PL (2012) The X chromosome and the sex ratio of autoimmunity. Autoimmun Rev 11:A531-A537

12. Quintero OL, Amador-Patarroyo MJ, Montoya-Ortiz G, RojasVillarraga A, Anaya JM (2012) Autoimmune disease and gender: plausible mechanisms for the female predominance of autoimmunity. J Autoimmun 38:J109-J119

13. Scofield RH, Bruner GR, Namjou B, Kimberly RP, RamseyGoldman R, Petri M, Reveille JD, Alarcón GS, Vilá LM, Reid J, Harris B, Li S, Kelly JA, Harley JB (2008) Klinefelter's syndrome $(47, \mathrm{XXY})$ in male systemic lupus erythematosus patients: support 
for the notion of a gene-dose effect from the $\mathrm{X}$ chromosome. Arthritis Rheum 58:2511-2517

14. S D, Aggarwal R, Harding JW et al (2011) Klinefelter's syndrome (47,XXY) among men with systemic lupus erythematosus. Acta Paediatr 100:819-823

15. Bianchi I, Lleo A, Gershwin ME, Invernizzi P (2012) The X chromosome and immune associated genes. J Autoimmun 38:J187J192

16. Friedman EA, Rutherford JW (1956) Pregnancy and lupus erythematosus. Obstet Gynecol 8:601-610

17. Doria A, Tincani A, Lockshin M (2008) Challenges of lupus pregnancies. Rheumatology 47(Suppl3):iii9-ii12

18. Khamashta MA (2006) Systemic lupus erythematosus and pregnancy. Clin Rheumatol 20:685-694

19. Lateef A, Petri M (2012) Management of pregnancy in systemic lupus erythematosus. Nat Rev Rheumatol 8:710-718

20. Ornoy A, Chen L, Silver RM, Miller RK (2004) Maternal autoimmune diseases and immunologically induced embryonic and fetoplacental damage. Birth Defects Res A Clin Mol Teratol 70: 371-381

21. Branch DW (1990) Autoimmunity and pregnancy loss. JAMA 264: 1453-1454

22. Yan Yuen S, Krizova A, Ouimet JM, Pope JE (2008) Pregnancy outcome in systemic lupus erythematosus (SLE) is improving: results from a case control study and literature review. Open Rheumatol J 2:89-98

23. Faussett MB, Branch DW (2000) Autoimmunity and pregnancy loss. Semin Reprod Med 18:379-392

24. Dhar JP, Essenmacher LM, Ager JW, Sokol RJ (2005) Pregnancy outcomes before and after a diagnosis of systemic lupus erythematosus. Am J Obstet Gynecol 193:1444-1455

Publisher's note Springer Nature remains neutral with regard to jurisdictional claims in published maps and institutional affiliations. 